\title{
Immunohistochemical identification of tumours of adipocytic differentiation using an antibody to aP2 protein
}

\author{
J H Bennett, S Shousha, B Puddle, N A Athanasou
}

\begin{abstract}
Aim-To determine whether aP2 expression is a useful diagnostic marker in soft tissue tumour pathology.

Methods-A polyclonal antibody to aP2 was used to investigate the immunohistochemical expression of this protein in benign and malignant tumours of adipocytic differentiation and a wide variety of other neoplasms.

Results-aP2 was only expressed by lipoblasts (in all types of liposarcoma and in lipoblastomatosis) and by brown fat cells (in both hibernomas and normal periadrenal fetal fat). Other benign adipose tissue tumours and malignant connective tissue or epithelial tumours were distinguished from liposarcoma by the absence of staining for aP2.

Conclusion-Identification of lipoblasts using markers of aP2 expression is of value in the differential diagnosis of benign and malignant adipose tissue tumours and in distinguishing liposarcomas from other malignant mesenchymal and epithelial neoplasms, some of which contain cells that morphologically resemble lipoblasts. (f Clin Pathol 1995;48:950-954)
\end{abstract}

Keywords: Liposarcoma, lipoma, adipose tissue, fat, sarcoma, lipoblast.

Department of Oral Pathology, Eastman Dental Hospital, 256 Gray's Inn Road London WCIX 8LD J H Bennett

Department of Histopathology, Charing Cross and Westminster Medical School,

Fulham Palace Road, London W6

S Shousha

Department of Pathology, Nuffield Orthopaedic Centre,

Oxford OX3 7LD

B Puddle

N A Athanasou

Correspondence to: $\operatorname{Dr} \mathrm{N} A$ Athanasou. Accepted for publication 18 January 1995
Tumours of adipose tissue, both benign and malignant, are among the commonest of the soft tissue tumours. ${ }^{1}$ As they are sometimes difficult to distinguish morphologically from tumours arising from other mesenchymal tissues, they can present a diagnostic problem to tumour pathologists. Differentiation of the various forms of benign and malignant adipose tissue tumours can also be problematic, particularly with regard to establishing a diagnosis of liposarcoma. One reason for these difficulties is that there are currently no specific histochemical or immunohistochemical markers of adipocytic differentiation and therefore diagnosis often depends on the recognition of a number of subtle morphological features which indicate that a tumour is of adipocytic differentiation.

Maturing prenatal adipocyte precursors include primitive spindle or stellate shaped fibroblast-like cells, containing little or no lipid, and more mature lipoblasts that contain one or more large cytoplasmic vacuoles and intracellular glycogen.$^{1-3}$ In a pathological context the presence of lipoblasts is generally regarded as indicative of a tumour of adipocytic differentiation: specifically, one of the various forms of liposarcoma or, more rarely, one of the infantile or childhood forms of lipoblastoma. ${ }^{1}$ Accurate identification of lipoblasts is thus of some importance as their presence often signals a diagnosis of malignancy in a well differentiated adipose tissue tumour, or designation of a malignant tumour as a liposarcoma rather than another form of soft tissue sarcoma. The morphological identification of lipoblasts, however, can, on occasion, be a difficult exercise and a cause of some debate among tumour pathologists.

Adipocytic differentiation has been intensively studied in vitro using preadipocytic cell lines. From these, genes regarded as early or late markers of adipocytic differentiation have been cloned. ${ }^{3-6}$ Their protein products are associated with the regulation of lipogenesis, lipolysis, triglyceride metabolism, or are known transcription factors. Examples include insulin regulated glucose transporter (IRGT or Glut4), lipoprotein lipase, glycerol-3-phosphate dehydrogenase, fatty acid synthetase, malic enzyme, aP2 ${ }^{78}$ and adipsin. ${ }^{910}$ Although expression of some of these proteins is not confined to adipose tissue, expression of others, including adipsin and aP2, is uniquely restricted to fat cells. aP2 (also known as p422 or adipocyte lipid binding protein), originally isolated from the murine 3T3-L1 cell line, is a 132 amino acid, single chain, $14.6 \mathrm{kD}$ polypeptide, showing considerable homology with myelin P2 proteins. It is encoded by a 0.6 kilobase mRNA and is expressed in preadipocytes late in adipogenesis. Its expression is coincident with acquisition of morphological features of the adipocyte phenotype.

To date, the expression of fat differentiation markers in neoplastic tissues has not been studied. Accordingly, using immunohistochemical techniques, we have studied the expression of the aP2 protein in a range of neoplasms, largely soft tissue tumours, in order to determine whether this protein can be used to distinguish adipocyte precursors, notably lipoblasts, in tumours of adipose tissue. We have investigated whether aP2 expression can be used as a diagnostic aid to differentiate between benign and malignant adipose tissue tumours. We have also examined whether other mesenchymal and epithelial neoplasms, some of which contain 
Tumours of adipose tissue and other lesions and tissues studied and results of staining for aP2

\begin{tabular}{|c|c|}
\hline Tumours of adipose tissue & $\begin{array}{l}\text { aP2 positive reaction/ } \\
\text { no. of lesions studied }\end{array}$ \\
\hline Lipoma & $0 / 10$ \\
\hline Pleomorphic lipoma & $0 / 2$ \\
\hline Intramuscular lipoma & $0 / 5$ \\
\hline Spindle cell lipoma & $0 / 8$ \\
\hline Lipoblastoma & $2 / 2$ \\
\hline Hibernoma & $3 / 3$ \\
\hline \multicolumn{2}{|l|}{ Liposarcoma } \\
\hline well differentiated & $4 / 7$ \\
\hline myxoid & $13 / 14$ \\
\hline round cell. & $6 / 6$ \\
\hline pleomorphic & $10 / 14$ \\
\hline \multicolumn{2}{|l|}{ Other tumours/tissues } \\
\hline Myxoma (intramuscular) & $0 / 5$ \\
\hline Benign fibrous histiocytoma & $0 / 2$ \\
\hline Fibromatosis (extra-abdominal desmoid) & $0 / 4$ \\
\hline Glomus tumour & $0 / 3$ \\
\hline Haemangioma & $0 / 2$ \\
\hline Neurilemmoma & $0 / 2$ \\
\hline Epithelioid sarcoma & $0 / 2$ \\
\hline Malignant fibrous histiocytoma & $0 / 5$ \\
\hline Synovial sarcoma & $0 / 4$ \\
\hline Ewing's tumour & $0 / 6$ \\
\hline Clear cell sarcoma & $0 / 2$ \\
\hline Rhabdomyosarcoma (embryonal) & $0 / 4$ \\
\hline Leiomyosarcoma & $0 / 4$ \\
\hline Osteosarcoma (soft tissue) & $0 / 1$ \\
\hline Clear cell carcinoma of kidney & $0 / 3$ \\
\hline Signet ring cell carcinoma of stomach & $0 / 2$ \\
\hline Renal/thyroid oncocytomas & $0 / 4$ \\
\hline \multicolumn{2}{|l|}{ Mature } \\
\hline subcutaneous & $0 / 4$ \\
\hline omental $\quad$ adipose tissue & $0 / 4$ \\
\hline retroperitoneal ) & $0 / 2$ \\
\hline Fetal periadrenal fat & $2 / 2$ \\
\hline \multirow{2}{*}{$\begin{array}{l}\text { Brain, liver, heart, pancreas, spleen, lung, striated muscle, } \\
\text { small bowel mucosa, kidney, adrenal gland, cartilage, bone }\end{array}$} & \\
\hline & all $0 / 2$ \\
\hline
\end{tabular}

cells that morphologically resemble lipoblasts and other adipocyte precursors, can be similarly distinguished from malignant tumours of adipocytic differentiation.

\section{Methods}

Cases of tumours of adipose tissue, other benign and malignant tumours as well as a range of normal tissues were retrieved from consultation files of the Nuffield Orthopaedic Centre, John Radcliffe Hospital and Charing Cross Hospital Histopathology Departments. Case material was in the form of unstained slides of tumours referred for histological opinion or paraffin wax blocks of tissue specimens (routinely fixed in formalin for at least 24 hours and embedded in paraffin wax) from which $5 \mu \mathrm{m}$ sections were cut and mounted onto glass slides. The number and range of tumours and tissues studied are shown in the table. Histological criteria used for the pathological diagnosis of the various soft tissue tumours examined were those of Enzinger and Weiss. ${ }^{1}$

The anti-aP2 antibody used was raised in rabbits against a synthetic peptide corresponding to the amino acid sequence of residues 121 to 132 of aP2 protein isolated from $3 \mathrm{~T} 3-\mathrm{LJ}$ cells $^{8}$ (kindly supplied by Dr M D Lane, Department of Biological Chemistry, Johns Hopkins Medical School, Baltimore, Maryland, USA). This sequence shows complete homology between mouse and man. ${ }^{6}$

Immunohistochemical staining was carried out using a two stage, indirect immunoperoxidase technique as described previously. ${ }^{10}$ Some sections which reacted weakly or not at

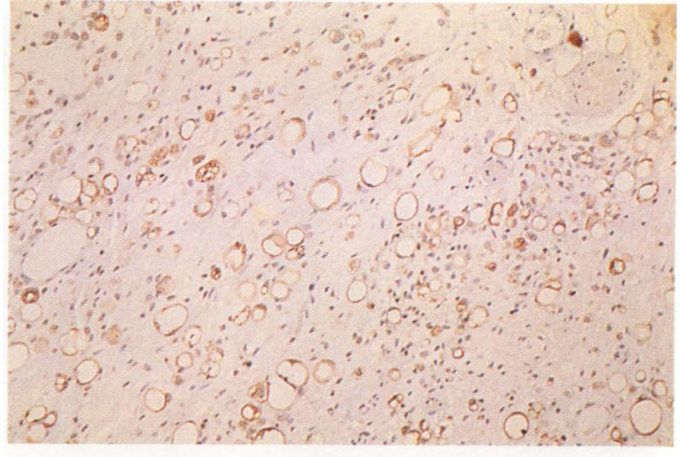

(A)

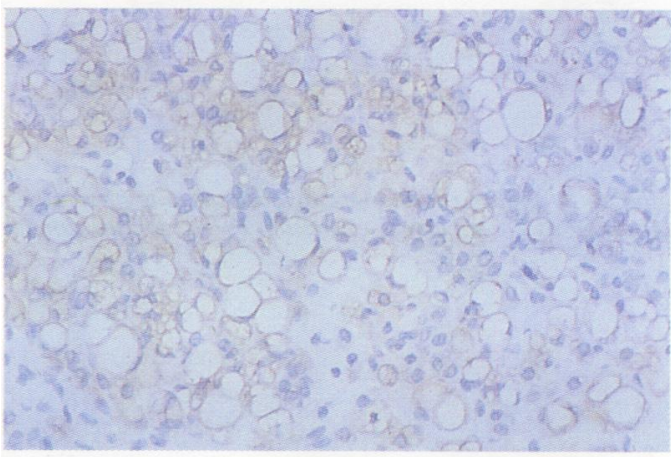

(B)

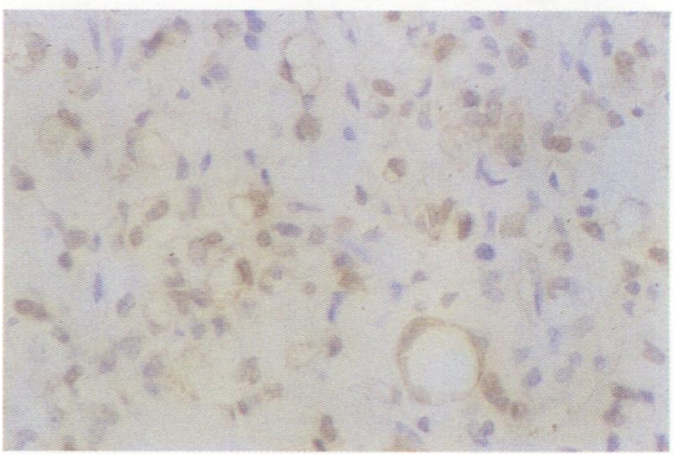

(C)

Figure 1 Indirect immunoperoxidase staining for aP2 in (A) a myxoid liposarcoma $(\times 200)$ and a round cell liposarcoma at $(B)$ low power $(\times 250)$ and at $(C)$ high power.

all with antibody directed against aP2 were pretreated in a microwave oven at $640 \mathrm{~W}$ for 10 minutes in $0.01 \mathrm{M}$ citrate buffer, $\mathrm{pH} 6 \cdot 0,{ }^{11}$ prior to staining to enhance immunohistochemical staining.

\section{Results}

Following staining of a wide variety of normal tissues and benign and malignant pathological lesions, we found that the aP2 gene product was expressed only by brown fat cells in periadrenal fetal fat and by hibernomas and lipoblasts in lipoblastomas, and by all types of liposarcoma (table).

Morphologically identifiable lipoblasts were clearly stained in both lipoblastoma and liposarcoma lesions (fig 1). A variable proportion of spindle shaped, round and pleomorphic cells 


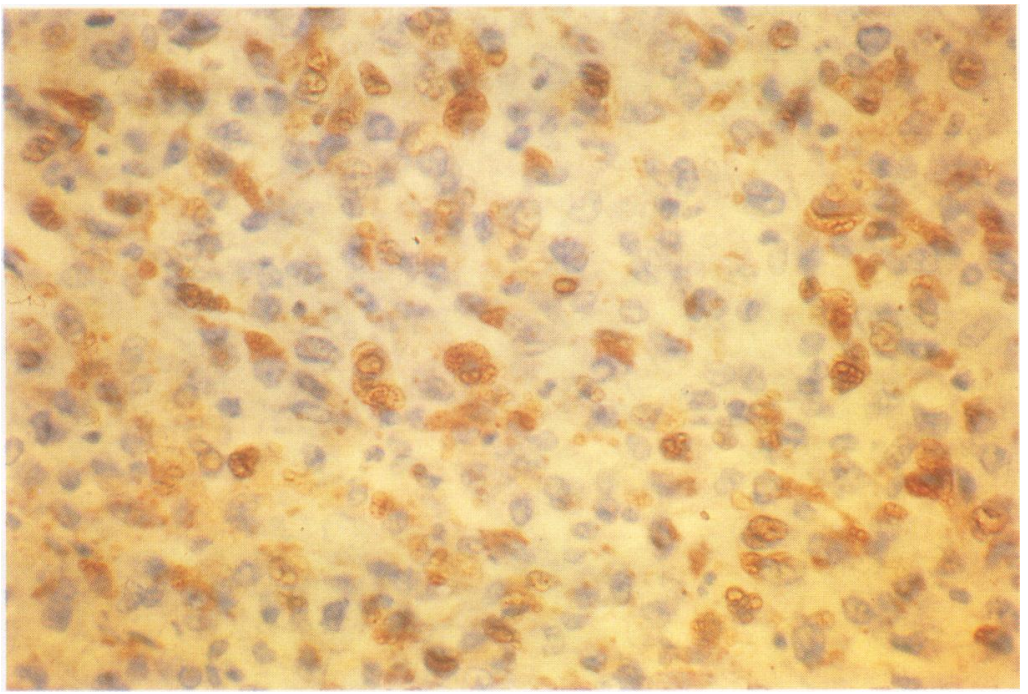

Figure 2 Indirect immunoperoxidase staining of a pleomorphic variant of liposarcoma showing aP2 cytoplasmic expression by vacuolated tumour cells $(\times 250)$.

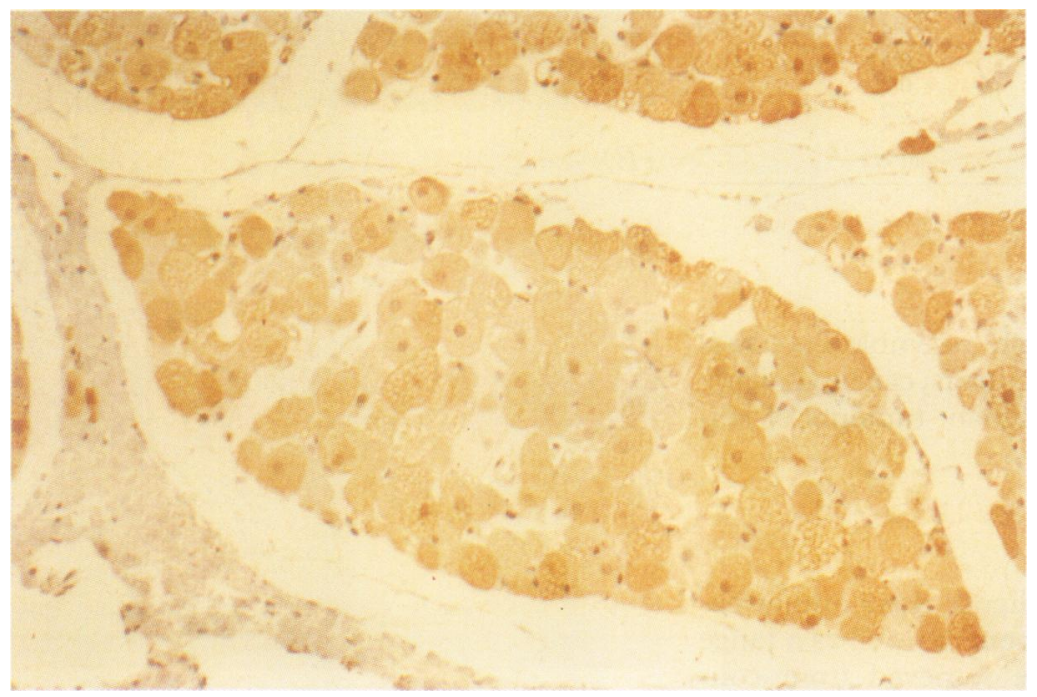

Figure 3 Indirect immunoperoxidase staining of a hibernoma for aP2 showing heavy positive staining of vacuolated brown (fetal) fat cells within the fatty lobules of the hibernoma $(\times 200)$.

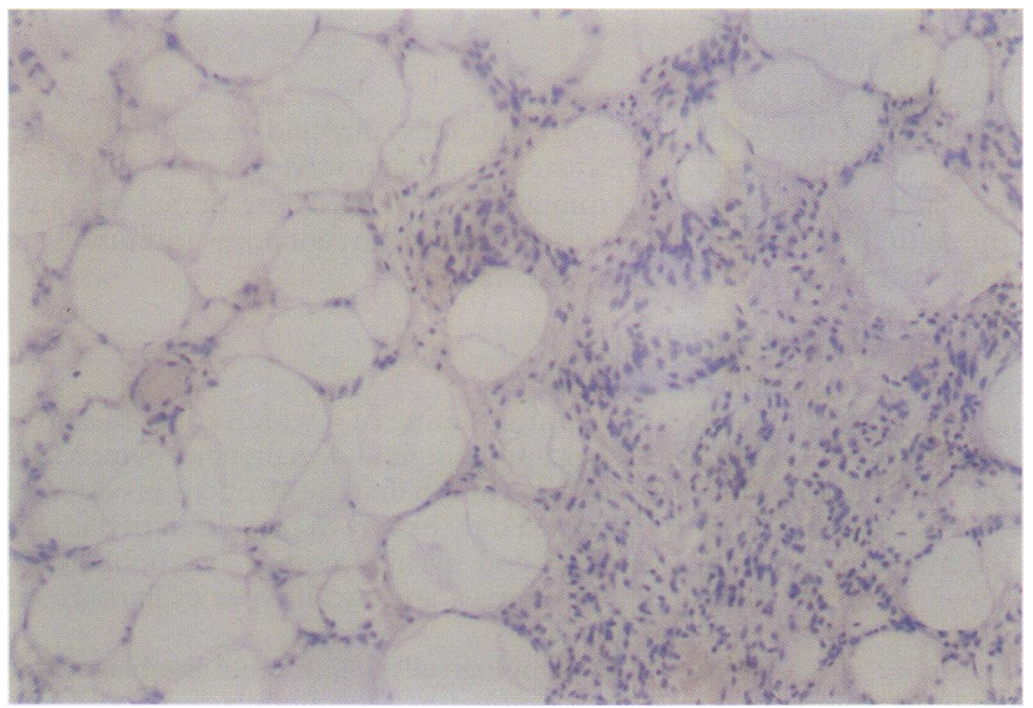

Figure 4 Indirect immunoperoxidase staining of a spindle cell lipoma showing the absence of staining for aP2 in fat and spindle cells $(\times 200)$. containing small fat vacuoles in pleomorphic variants of liposarcoma were also aP2 positive (fig 2). aP2 staining was restricted to the cytoplasm and most often localised around the periphery of the small fat vacuole within lipoblasts. In those areas of pleomorphic liposarcoma where spindle, round or pleomorphic tumour cells predominated, staining for aP2 was also cytoplasmic, often highlighting the presence of small fat vacuoles which were not evident on routine staining with haematoxylin and eosin.

A greater number of aP2 positive cells were seen in myxoid, round cell and pleomorphic variants of liposarcoma compared with well differentiated forms of this tumour. This confirms the morphological observation that lipoblasts and other primitive fat precursor cells are less commonly observed in well differentiated lipoma-like or sclerosing variants of liposarcoma compared with myxoid, round cell and pleomorphic types of liposarcoma. Microwave pretreatment enhanced staining of brown fat cells and lipoblasts in sections of hibernoma and liposarcoma, respectively, although this was generally achieved at the cost of increased background staining. A few sections of referred cases of liposarcoma were entirely aP2 negative, possibly indicating weak expression of the aP2 antigen in these particular tumours, or unknown variability in fixation and processing of these tumours.

aP2 was also strongly expressed by brown fat cells in normal periadrenal fetal fat and in hibernomas (fig 3). aP2 was largely localised around the small fat vacuoles within the cytoplasm of these cells. Normal mature subcutaneous, omental and retroperitoneal adipose tissue as well as fat entrapped or infiltrated by the many other soft tissue lesions examined, showed no evidence of aP2 staining. Two lesions of subcutaneous fat necrosis were also entirely negative for aP2. With the exception of hibernoma, all benign adipose tissue tumours (including cases of pleomorphic lipoma and spindle cell lipoma) were negative for aP2 (fig 4). Both of the pleomorphic lipomas and several of the spindle cell lipomas studied contained fat cells showing marked variation in size, including small cells that morphologically resembled lipoblasts; these lipoblast-like cells were aP2 negative.

A variety of normal tissues were screened and found to be negative for aP2. A wide range of benign and malignant non-adipose soft tissue tumours of mesenchymal and epithelial differentiation were also negative. In particular, aP2 was not expressed by several malignant tumours containing vacuolated cells which morphologically resembled lipoblasts, such as leiomyosarcoma, clear cell sarcoma, clear cell carcinoma, and signet ring cell carcinoma. Renal oncocytomas and thyroid Hürthle cell tumours, both of which contain mitochondriarich tumour cells that resemble brown fat cells, were also aP2 negative. Other tumours containing numerous round or pleomorphic cells, such as Ewing's sarcoma, rhabdomyosarcoma or malignant fibrous histiocytoma, were also negative for $\mathrm{aP2}$. 


\section{Discussion}

This study has shown that immunohistochemical staining for the aP2 gene product can be used to identify lipoblasts and brown fat cells in tissue sections. With the exception of hibernoma and lipoblastoma, expression of aP2 was only seen in liposarcomas. Expression of aP2 therefore provides a means of distinguishing liposarcoma from most common benign tumours of adipocytic differentiation. Similarly, other malignant epithelial and connective tissue tumours containing round or vacuolated cells, showing some morphological resemblance to lipoblasts and other primitive adipocyte precursors, can also be distinguished from liposarcomas because of the absence of staining for aP2.

There are no specific enzyme or lipid histochemical markers of adipocytic differentiation. ${ }^{12}$ Lipid histochemical stains such as oil red $O$ and Sudan IV are of limited use as they require specific fixation and processing protocols. Lipids are lost after prolonged fixation in formaldehyde and lipid histochemistry cannot be used on sections of routinely processed, paraffin wax embedded tissues. These stains are also of limited diagnostic use as they are not specific; tumour cells in a variety of other mesenchymal and epithelial neoplasms also contain histochemically identifiable lipid. ${ }^{12}$ Lipomas and liposarcomas have been reported to be positive for vimentin and variably positive for $S 100^{1212}$; however, these proteins are expressed in a wide range of soft tissue tumours, so they are of relatively little use in characterising a tumour as one of adipocytic differentiation. Moreover, the above histochemical and immunohistochemical markers do not distinguish between benign and malignant adipose tissue tumours. Immunohistochemical identification of aP2 expression is thus likely to be particularly valuable in tumour diagnosis as it not only identifies lipoblasts, the cytological hallmark of a malignant adipose tissue tumour, but also allows this to be carried out in formalin fixed, routinely processed tissue sections.

Benign adipose tissue tumours such as spindle cell lipoma or pleomorphic lipoma may contain small or pleomorphic fat cells that may resemble lipoblasts. ${ }^{1}$ In about $50 \%$ of pleomorphic lipomas, cells morphologically indistinguishable from lipoblasts have been noted. ${ }^{1314}$ These cells, however, were entirely aP2 negative, aP2 being almost exclusively expressed by lipoblasts in liposarcomas. The high specificity of aP2 staining for lipoblasts in liposarcomas enables the pathologist to distinguish benign adipose tissue tumours containing lipoblast-like cells from liposarcomas. A lack of aP2 expression was also useful in determining the nature of small or compressed fat cells lying close to fibrous tissue within the benign adipose tissue tumours and in areas of fat necrosis or panniculitis containing small or degenerate fat cells which can be morphologically mistaken for lipoblasts.

Several morphological variants of liposarcoma are known to exist, ${ }^{1}$ each of which needs to be distinguished from a number of sarcomas and carcinomas. Thus, malignant tu- mours containing numerous pleomorphic or round tumour cells, such as rhabdomyosarcoma, Ewing's sarcoma or pleomorphic malignant fibrous histiocytoma, need to be distinguished from round cell or pleomorphic liposarcoma, both high grade forms of liposarcoma. Tumours such as myxoid malignant fibrous histiocytoma, intramuscular myxoma or benign or malignant nerve sheath tumours, containing abundant myxoid material in the stroma, need to be differentiated from myxoid liposarcoma. In addition, tumours with numerous clear or vacuolated cells, such as leiomyosarcoma, clear cell sarcoma, clear cell carcinoma, or signet ring cell carcinoma, may be confused with a liposarcoma containing abundant lipoblasts. As aP2 expression in malignant tumours is restricted to liposarcomas, identification of this antigen provides a valuable marker of adipocytic differentiation, aiding histological recognition of this tumour.

Although most liposarcomas and all hibernomas were aP2 positive and a few tumours showed weak staining for this antigen, five liposarcomas and one lipoblastoma remained negative. These differences in staining may have been due to variations in the processing or fixation of these tumours or because some lipoblasts show little or no expression of the aP2 antigen. Pretreating the slides in a microwave oven enhanced staining. ${ }^{11}$

Fat cells vary in size and shape from spindle or round fibroblast-like cells (prolipoblasts), round cells (lipoblasts) containing little lipid, multivacuolated cells containing many lipid filled vacuoles (preadipocytes) to mature fat cells in which the small vacuoles have coalesced to form a single, large, round, fat vacuole filling the cytoplasm (adipocytes). ${ }^{23}$ The aP2 gene is only expressed upon adipocytic differentiation and levels of expression in cultured cell lines are known to be differentiation dependent. ${ }^{78}$ It is regarded as a late, as opposed to a very late, marker of differentiation. ${ }^{15}$ In vitro, aP2 expression has been correlated with the acquisition of the morphological features of preadipocytes and young adipocytes and is lost in more mature cells with extensive cytoplasmic lipid vacuolation. ${ }^{16}$ This is reflected in our findings where aP2 staining was seen around small fat vacuoles within prolipoblast and lipoblast-like cells of immature fat, lipoblastoma and liposarcoma, but not in adipocytes of mature fat or the various forms of lipoma studied.

Fetal adipose tissue develops from aggregates of mesenchymal cells which condense around proliferating primitive blood vessels. ${ }^{23}$ The precise nature of the stromal cell from which adipocytes originate is uncertain. In vitro studies suggest that they are derived from a primitive pluripotent cell which gives rise to other cellular elements of the mesenchyme, such as fibroblasts, chondrocytes, myoblasts, and osteoblasts. ${ }^{1718}$ Phenotypic differentiation markers are slowly becoming available for several cell lineage products of this putative stromal precursor. Our finding that immature fat cells in adipose tumours express aP2 raises the exciting possibility that identification of lineage specific antigens may assist in the diag- 
nosis of other soft tissue neoplasms. Indeed, the MyoD1 protein, specific to muscle, has been used successfully in this way to diagnose rhabdomyosarcoma. ${ }^{19}$ Further characterisation of the pattern of expression of these proteins in pathological specimens may allow diagnosis of soft tissue tumours to be carried out using immunophenotypic markers in a manner analogous to that used for the diagnosis of haematological malignancies.

We would like to thank Mrs L Akers for typing the manuscrip and Dr S Gould for supplying some of the paediatric material for this study. This study was supported by the BOA Wishbone Trust.

1 Enzinger FM, Weiss SW. Soft tissue tumors. 2nd edn. St Louis: Mosby, 1988

2 Poissonet CM, La Velle M, Burds AR. Growth and development of adipose tissue. F Pediatr 1988;113:1-9.

3 Brooks JJ, Perosio PM. Adipocytic tissue. In: Sternberg S, ed. Histology for pathologists. New York: Raven Press, 1992 33-61

4 Ailhaud G, Amri E, Bardon S, Barcellini-Couget S, Bertrand $\mathrm{B}$, Catalioto RM, et al. Growth and differentiation of regional adipose tissue: molecular and hormonal mechregional adipose tissue: molecular and horm
anisms. Int $\mathcal{f}$ Obes 1991;15(Suppl 2):87-90.

anisms. Int $\mathcal{f}$ Obes 1991;15(Suppl 2):87-90. 1991;5:287-94.

6 Spiegelman BM, Choy L, Hotamisligil GS, Graves RA, Tontonoz P. Regulation of adipocyte gene expression in differentiation and syndromes of obesity/diabetes. $\mathcal{F}$ Bio Chem 1993;268:6823-6.

7 Bernlohr DA, Angus CW, Lane MD, Bolanowski MA, Kelly T. Expression of specific mRNAs during adipose differentiation, identification of an mRNA encoding homologue of myelin P2 protein. Proc Natl Acad Sci USA 1984;81:5468-72.

8 Bernlohr DA, Doering TL, Kelly TJ, Lane MD. Tissue specific expression of $\mathrm{p} 422$ protein, a putative lipid carrier,
in mouse adipocytes. Biochem Biophys Res Commun 1985; in mouse adi

9 Baxa CA, Sha RS, Buelt MK, Smith AJ, Smith AJ, Matarese $\mathrm{V}$, Chinander LL, et al. Human adipocyte lipid-binding protein: purification of the protein and cloning of its complementary DNA. Biochemistry 1989;28:8683-90.

10 Sternberger A. Immunocytochemistry. New York: Wiley, 1986. 1 Cattoretti G, Pieri S, Parravicini C, Becker MC, Poggi S, Bifulco C, et al. Antigen unmasking on formalin-fixed, paraffin-embedded tissue sections. F Pathol 1993;171:8398.

12 Nakajima T, Watanabe S, Sato Y, Kameya T, Hirota T, Shimosato Y. An immunoperoxiclase study of $\mathrm{S} 100$ protein distribution in normal and neoplastic tissues. $A m \mathcal{F}$ Surg Pathol 1982;6:715-22.

13 Shmookler BM, Enzinger FM. Pleomorphic lipoma: a benign tumour simulating liposarcoma. A clinicopathological nign tumour simulating liposarcoma. A clinicopat

14 Azzopardi JG, Iocco J, Salm R. Pleomorphic lipoma: a tumour simulating liposarcoma. Histopathology 1983;7: 511-23.

15 Ailhaud G, Amri E, Barbaras R, Casteilla L, Catalioto RM, Dani C, et al. Adipose cell differentiation: differential expression of specific mRNA's and protein markers in cells from white and brown adipose tissues. In: Berry EM, Blondheim SH, Eliahou HE, Shafir E, eds. Recent advances in obesity research. Vol V. London, Paris: John Libbey, 1987:174-80.

16 Beresford JN, Bennett JH, Owen ME, LeBoy P. Expression of adipocytic and osteogenic differentiation markers in marrow

17 Grigoriadis AE, Heersche JNM, Aubin JE. Differentiation of muscle, fat, cartilage, and bone from progenitor cells present in a bone-derived clonal cell population: effect of Dexamethasone. $\mathcal{F}$ Cell Biol 1988;106:2139-51.

18 Taylor SM, Jones PA. Multiple new phenotypes induced in $10 \mathrm{~T}^{1}$ and $3 \mathrm{~T} 3$ cells treated with 5-Azacytidine. Cell 1979;17:771-9.

19 Dias P, Parham DM, Shapiro DN, Webber BL, Houghton PJ. Myogenic regulatory protein (MyoD1) expression in childhood solid tumors: diagnostic utility in childhood tumors. Am $\mathcal{F}$ Pathol 1990;137:1283-91. 